\title{
Conexões entre a prática da modelagem matemática e o desenvolvimento do pensamento critico-reflexivo a partir da etnomatemática
}

Connections between the practice of mathematical modeling and the development of reflective thought from ethnomathematics

\author{
Filicio Mulinari ${ }^{1}$ \\ Tercio Girelli Kill² \\ Felipe Nascimento Gaze ${ }^{3}$
}

\begin{abstract}
Resumo
Ao optar por conteúdos descontextualizados, exercícios e problemas padronizados repetidos à exaustão, o ensino da matemática tradicional prioriza uma aprendizagem descompromissada com a articulação de um pensamento crítico, além de escolher uma linguagem geralmente acessivel às classes que detêm um maior capital econômico e cultural. É uma matemática que exclui e que faz crer na existência de um talento natural para justificar o sucesso escolar. Contudo, tendo como base três teóricos que são referências sobre a educação matemática crítica (Skovsmose, 2001, 2008, 2014; D’ambrósio, 1986, 2005; Barbosa, 2001, 2004), o ensaio propõe uma investigação teórica sobre as possibilidades do uso da modelagem matemática como ferramenta para o ensino não ser um mero reprodutor das relações de exploração, mas um caminho para a emancipação e promoção do pensamento crítico e reflexivo. $O$ objetivo é promover uma reflexão sobre a prática da modelagem matemática na promoção de uma educação matemática crítica, mostrando sua relação com o desenvolvimento de um pensamento autônomo e emancipatório. Ao fim, esperamos concluir que o uso de modelos matemáticos é uma estratégia importante para que a educação
\end{abstract}

\footnotetext{
${ }^{1}$ Doutorando em Filosofia pela Universidade Federal de São Paulo. Mestre em Filosofia pela Universidade Federal do Espírito Santo. Professor efetivo do Instituto Federal do Espírito Santo. E-mail: filicio@gmail.com.

2 Doutor em Educação. Professor Efetivo vinculado ao Departamento de Educação da Universidade Federal do Espírito Santo (Ufes). E-mail: tercio.kill@gmail.com.

3 Professor de Matemática efetivo da Secretaria Estadual da Educação do Estado do Espírito Santo (Sedu). Mestre em Engenharia Ambiental (Ufes). E-mail: fngaze@gmail.com.
} 
matemática seja uma ferramenta crítica de interpretação de uma situação real.

Palavras-chave: Educação Matemática. Etnomatemática. Matemática critica. Modelagem.

\begin{abstract}
By choosing decontextualized content, exercises and standardized problems repeated to exhaustion, the teaching of traditional mathematics prioritizes uncompromising learning with the articulation of critical thinking, as well as choosing a language generally accessible to classes that hold greater economic and cultural capital. It is a mathematics that excludes and that makes believe in the existence of a natural talent to justify school success. However, based on three theorists who are references on critical mathematical education (Skovsmose, 2001, 2008, 2014; D'ambrósio, 1986, 2005; Barbosa, 2001, 2004), the paper proposes a theoretical investigation about the possibilities of use of mathematical modeling as a tool for teaching not to be a mere reproducer of the relations of exploration, but a way for the emancipation and promotion of critical and reflexive thinking. The objective is to promote a reflection on the practice of mathematical modeling in the promotion of a critical mathematical education, showing its relation with the development of an autonomous and emancipatory thought. Finally, we hope to conclude that the use of mathematical models is an important strategy for mathematical education to be a critical tool for interpreting a real situation.
\end{abstract}

Keywords: Mathematics Education. Ethnomathematics. Critical Mathematics. Modeling.

\title{
Introdução
}

Há em muitos teóricos - sobretudo escolanovistas - uma tendência em se enxergar a escola como um local de emancipação e ascensão social, um lugar que possui um papel essencialmente transformador na vida dos individuos. ${ }^{4}$ Trata-se de um entendimento oriundo daquilo que o

\footnotetext{
${ }^{4}$ A escola nova estava convencida de que a verdadeira democracia seria instaurada pela "escola redentora", na qual todos poderiam garantir "um lugar ao Sol" a partir de seu talento e esforço. Segundo Dewey, o desenvolvimento tecnológico e a vida democrática tinham na escola um instrumento ideal, por meio do qual os benefícios da educação seriam estendidos a todos, indistintamente. A escola teria a função democratizadora de equalizar as oportunidades. Eis aí, segundo alguns teóricos, o chamado "otimismo pedagógico" ou, ainda, a "ilusão liberal" da escola nova. Embora tenhamos de
} 
sociólogo Pierre Bourdieu (1998) chama de "inércia cultural", ou seja, uma visão que ignora os mecanismos objetivos que fazem da escola um local de exclusão e reprodução das desigualdades. Recorrendo às palavras do sociólogo, a escola seria “ (...) um dos fatores mais eficazes de conservação social, pois fornece a aparência de legitimidade às desigualdades sociais, e sanciona a herança cultural e o dom social tratado como dom natural" (BOURDIEU, 1998, p. 41). Nesse sentido, a escola ratificaria pela ideologia os mecanismos de promoção do poder dominante. ${ }^{5}$

Os instrumentos de preservação do poder dominante são apresentados no sistema escolar por um espectro de legitimidade, dotados de um processo avaliativo e de seleção baseados em critérios como mérito e talento, disfarçando uma pedagogia que beneficia classes mais favorecidas e relega às classes menos favorecidas uma desvalorização e exclusão que desembocam no fracasso escolar. Em outras palavras:

[...] propõe um tipo de informação e de formação acessiveis exclusivamente àqueles sujeitos dotados do sistema de disposições que constitui a condição do êxito da transmissão e da inculcação da cultura. Eximindo-se de oferecer a todos explicitamente o que exige de todos implicitamente, quer exigir de todos uniformemente que tenham o que não lhes foi dado, a saber, sobretudo a competência linguística e cultural e a relação de intimidade com a cultura e com a linguagem,

reconhecer os aspectos inovadores da contribuição de Dewey, sobretudo quanto à oposição à escola tradicional, essa pedagogia ainda se inscreve no horizonte dos ideais liberais e, como tal, se funda na aceitação, não no questionamento dos valores burgueses. Nesse sentido, a sociedade como tal não é colocada em questão em momento algum, como acontece nas teorias de inspiração socialista, em que, por exemplo, a noção de trabalho passa pelo crivo da análise ideológica (ARANHA, 1990, p. 170-171).

${ }^{5}$ Em uma linha de raciocínio próxima ao de Bourdieu nesse quesito, o filósofo marxista Althusser (1983) entendia que a escola seria hoje o que foi a igreja no passado, ou seja, o aparelho ideológico que mais efetivamente funciona como um reprodutor das relações de produção e exploração e, consequentemente, da conservação da doutrina dominante. Para Althusser, tem-se que "[...] a Escola (mas também outras instituições de Estado como a Igreja ou outros aparelhos como o Exército) ensinam $<<$ saberes práticos $>>$ mas em moldes que asseguram a sujeição à ideologia dominante ou o manejo da $<<$ prática >> desta. Todos os agentes da produção, da exploração e da repressão [...] devem estar de uma maneira ou de outra <<penetrados $>>$ desta ideologia, para desempenharem $<<$ conscienciosamente >> a sua tarefa - quer dos explorados (os proletários), quer de exploradores (os capitalistas), quer de auxiliares da exploração [...], quer de papas da ideologia dominante [...], etc..." (ALTHUSSER, 1983, p. 22). 
instrumentos que somente a educação familiar pode produzir quando transmite a cultura dominante (BOURDIEU, 2005, p. 306-307).

Na mesma esteira, Mészáros (2008) destaca que esse é um papel histórico da escola, agir no sentido contrário de uma consciência de classe para disponibilizar os meios necessários à manutenção do sistema de produção capitalista.

A educação institucionalizada [...] serviu - no seu todo - ao propósito de não só fornecer os conhecimentos e o pessoal necessário à máquina produtiva em expansão do sistema do capital, como também gerar e transmitir um quadro de valores que legitima os interesses dominantes, como se não pudesse haver nenhuma alternativa à gestão da sociedade, seja na forma "internalizada" (isto é, pelos indivíduos devidamente "educados" e aceitos) ou através de uma dominação estrutural e uma subordinação hierárquica e implacavelmente impostas (MÉSZÁROS, 2008, p. 35).

Esse viés conservador da educação está refletido nos moldes do ensino tradicional da matemática na Educação Básica brasileira. ${ }^{6}$ Ao optar por conteúdos descontextualizados, exercícios e problemas padronizados repetidos à exaustão para impor uma só maneira de resolução dada pelo professor para atingir uma única resposta correta, o ensino da matemática, além de priorizar uma aprendizagem descompromissada com a articulação de um pensamento critico, escolhe uma linguagem geralmente acessível às classes que detêm um maior

6 É dificil o desafio de delimitar um conceito tão extensor quanto o de "escola tradicional". Sob essa denominação articulam-se as mais diversas tendências no decorrer de pelo menos quarto ou cinco séculos (desde o século XVI até o século XX), período em que a escola tradicional sofreu inúmeras transformações. [...] Diante da dificuldade em analisar de forma homogênea o que seria a "escola tradicional", veremos em primeiro lugar o que chamamos genericamente de características gerais, mesmo correndo o risco das simplificações. [...] Quanto à relação entre professor e aluno, a educação tradicional é magistrocêntrica, isto é, centrada no professor e na transmissão dos conhecimentos. O mestre detém o saber e a autoridade dirige o processo de aprendizagem e se apresenta, ainda, como um modelo a ser seguido. Essa relação é vertical, porque hierárquica, tem como consequência, nos casos extremos, a passividade do aluno, reduzido a simples receptor da tradição cultural. Quanto à metodologia, é valorizada a aula expositiva, centrada no professor, com destaque para situações em sala de aula nas quais são feitos exercícios de fixação, com leituras repetidas e cópias. Submetidos a horários e currículos rígidos, os alunos são considerados um bloco único e homogêneo, não havendo qualquer preocupação com as diferenças individuais (ARANHA, 1990, p. 157-158). 
capital econômico e cultural. ${ }^{7}$ É uma matemática excludente, selecionadora de elites, que faz crer na existência de um talento natural para justificar o sucesso escolar.

Logo, partindo dos principais autores da área (Skovsmose, 2001, 2008, 2014; D’ambrósio, 1986, 2005; Barbosa, 2001, 2004) e buscando outros trabalhos na literatura, o artigo propõe uma investigação e reflexão sobre as possibilidades do uso da modelagem matemática como ferramenta para o ensino não ser um mero reprodutor das relações de exploração, mas sim um caminho para a emancipação e promoção do pensamento crítico e reflexivo. O objetivo é promover uma reflexão sobre a prática da modelagem matemática na promoção de uma educação matemática crítica, mostrando sua relação com o desenvolvimento de um pensamento autônomo e emancipatório

\section{O ensino tradicional de matemática e a naturalização do fracasso}

Segundo o pesquisador dinamarquês Ole Skovmose (2014), há no modelo tradicional de ensino da matemática uma predominância de exercícios pelos quais o aluno, para ter êxito, deve seguir cegamente um conjunto de instruções pré-determinadas pela autoridade do professor, assemelhando-se à rotina de obediência sem questionamentos que se espera dos participantes das relações de produção do mercado de trabalho. A matemática, entendida sob esta perspectiva, prezaria por uma submissão às ordens e uma apatia social e politica, da mesma forma que a estrutura econômica neoliberal deseja daqueles que ocupam os postos de trabalho.

7 Capital cultural é um conceito desenvolvido em algumas das obras de Pierre Bourdieu (1998; 2016) para tratar as relações de classe em uma sociedade e analisar como a cultura reflete e atua sobre os indivíduos. Capital cultural seria a gama de conhecimento, linguagem, estilos, gestos, modos de falar, de se vestir, gostos e expressões culturais tomados como legitimos e que gozam de uma posição de valor e poder na sociedade e dentro das escolas e universidades. São, geralmente, as manifestações culturais e sociais associadas e restritas às classes de pessoas mais privilegiadas econômica e socialmente. 
Toda a informação contida no enunciado [do exercício matemático] deve ser recebida como algo fechado, exato e suficiente. Ou, mais especificamente, as informações do exercício são compreendidas como necessárias e suficientes para resolvê-lo. [...] Isso nos remete ao principal aspecto da industrialização: o controle da mão de obra. Um dos dispositivos fundamentais da revolução industrial foi reunir e confinar os trabalhadores nas fábricas, fornecendo a eles todas as ferramentas necessárias para realizar as tarefas, de modo que eles não precisassem mais se deslocar durante o período de trabalho. Uma lógica similar também está presente no ensino de matemática tradicional. Toda a informação está à disposição, e os alunos podem permanecer quietos em suas carteiras resolvendo exercícios (SKOVSMOSE, 2014, p. 17).

D’Ambrósio (2005) complementa a relação do ensino da matemática com o sistema de produção capitalista quando observa que a matemática, como outras linguagens, é utilizada como um meio de seleção e eliminação dentro das instituições escolares.

A escola ampliou-se, acolhendo jovens do povo, aos quais se oferece a possibilidade de acesso social. Mas esse acesso se dá em função de resultados, que são uma modalidade de cooptação. Sistemas adequados para a seleção dos que vão merecer acesso são criados e justificados por convenientes teorias de comportamento e de aprendizagem. Um instrumento seletivo de grande importância é a linguagem. O latim foi padrão, depois substituído pela norma culta da linguagem. Ainda hoje, muitas crianças se inibem ao falar porque sabem que falam errado e, como não são capazes de falar certo, silenciam. Logo, a matemática também assumiu um papel de instrumento de seleção. E sabemos que muitas crianças ainda são punidas por fazerem contas com os dedos (D’AMBRÓSIO, 2005, p. 40-41).

O estudante, ao se deparar com uma matemática que abstrai toda uma relação de investigação com seu universo sociocultural e institui uma linguagem autoritária e em descompasso com a sua, tende a naturalizar as questões de dominação e aceitar mais passivamente a seletividade do aprendizado matemático. Dentro da sala de aula, por exemplo, é comum apontar - num julgamento tanto dos alunos quanto do professor - estudantes mais e menos capacitados. Aqueles que "nasceram" para dominar os códigos da álgebra e da geometria em 
oposição àqueles para os quais a matemática é uma linguagem tão distante quanto uma língua estrangeira pouco conhecida. ${ }^{8}$

Skovsmose (2001) estende esse raciocínio e mostra como ele se reflete nas posições dentro de uma sociedade altamente tecnológica, que tem na matemática uma importante ferramenta para sua promoção e análise das consequências do seu desenvolvimento.

Estudantes aprendem (também) a seguir prescrições explicitamente estabelecidas: "Resolva a equação ...", "Acha a medida de ...", "Calcule o valor de ..." etc. Isso não tem muito em comum com os processos reais de investigações ou maneiras criativas de estruturar problemas. Tem muito mais em comum com instruções e regulamentações com as quais muitas pessoas nos processos de rotina de trabalho confrontam. [...] Os estudantes aprendem que algumas pessoas são capazes de gerenciar problemas tecnológicos, e que algumas pessoas não são. Consequentemente, os estudantes "incapazes" aprendem a se tornar servis em relação às questões tecnológicas e tornam-se servis em relação àqueles que podem lidar com elas (SKOVSMOSE, 2001, p. 45-46).

Diante desse cenário, o desafio da escola e, consequentemente, do ensino da matemática, é romper com esse modelo que naturaliza o fracasso e chegar a um processo no qual a escola seja um lugar de

\footnotetext{
8 Sobre a naturalização do fracasso, temos as seguintes conclusões de um importante estudo sobre o tema: "O presente estudo nos possibilitou compreender como a queixa/fracasso escolar, no que tange às dificuldades de aprendizagem, vem sendo divulgada em periódicos científicos de grande circulação no Brasil. Pela leitura e análise dos 77 artigos encontrados identificamos quatro grandes eixos que embasaram as concepções que fundamentam as reflexões neles presentes sobre a queixa/fracasso escolar: 1) queixa/fracasso escolar centrada no indivíduo; 2) queixa/fracasso escolar como questão institucional; 3) queixa/ fracasso escolar relacionada à formação profissional; e 4) queixa/fracasso escolar não centrada no indivíduo. A partir das informações encontradas, verificamos uma grande ênfase nas concepções individualizantes em relação à queixa/fracasso escolar, evidenciada pela apologia exacerbada ao potencial intelectual considerado inato, próprio de cada indivíduo. Desta forma, o processo de escolarização vem sendo encarado como responsabilidade individual - do aluno, do professor ou da família. Esta individualização desconsidera a totalidade que envolve o processo de escolarização e, ao culpabilizar o indivíduo, retira a responsabilidade da sociedade baseada no modo de produção capitalista, sistema que implica divisão de classes, relações sociais antagônicas, domínio de uma classe sobre as outras, a necessidade de manter um equilíbrio entre os homens - mesmo que aparente, uma vez que não há equilíbrio possivel entre pessoas de classes antagônicas - e outras consequências, enfraquecendo nos trabalhadores a capacidade de lutar por seus direitos. Neste sentido, o tipo de organização escolar existente responde à necessidade da sociedade de se perpetuar, mediante a formação de indivíduos adaptados e submissos, que reconheçam em si mesmos a possibilidade de sucesso e responsabilizem-se por seu fracasso, isentando o meio social. " (LEONARDO; LEAL; ROSSATO, 2015, p. 168-169).
} 
emancipação e realização genuína. ${ }^{9}$ Uma instituição crítica onde os educandos exerçam sua cidadania e, recorrendo às palavras de Mészáros (2008, p. 48), "proporcione instrumentos de pressão que rompam com a lógica mistificadora do capital”. Esse parece ser o axioma básico de uma educação crítica.

O axioma básico da EC [educação crítica] é que a educação não deve servir como reprodução passiva de relações sociais existentes e de relações de poder. Esse axioma faz sentido quando falamos sobre competência critica, distância crítica e engajamento crítico. A educação tem de desempenhar um papel ativo na identificação e no combate de disparidades sociais (SKOVSMOSE, 2001, p. 32).

Nessa perspectiva, temos que uma educação crítica passa por desenvolver na escola práticas pedagógicas que assumam o compromisso com experiências culturais, de consciência de classe, que manifestem uma luta social e política. Um processo educacional libertador de desalienação e inclusão. ${ }^{10}$

\section{Do respaldo legal sobre o ensino de matemática}

Mais do que uma necessidade, a transformação para uma escola libertadora, que tome um posicionamento crítico, é uma obrigação prevista em lei. Desde o seu ano de vigência, em 1996, a Lei de diretrizes e bases da educação nacional (Lei nº 9394/96) já inseria essa perspectiva para a Educação Básica nacional. Além de estabelecer, no artigo $1^{\circ}$, que "A educação deverá vincular-se ao mundo do trabalho e à prática social" (BRASIL, 1996), a LDB ainda estende esse conceito, sobretudo em seu artigo 3, quando elenca os princípios do ensino ministrado na educação

\footnotetext{
9 O conceito de emancipação é baseado no tratamento encontrado no Dicionário do pensamento marxista (BOTTOMORE, 2001, p. 123-124), onde afirma que "Marx e os marxistas tendem a ver a liberdade em termos da eliminação dos obstáculos à emancipação humana, isto é, ao múltiplo desenvolvimento das possibilidades humanas à criação de uma forma de associação digna da condição humana".

10 É interessante notar que o pesquisador dinamarquês Ole Skovsmose tem, para a educação, um pensamento que se aproxima do educador brasileiro Paulo Freire, que afirma que "ensinar não é transferir conhecimento, mas criar as possibilidades para a sua produção ou a sua construção" (FREIRE, 2010, p. 22). É uma reflexão que serve para pensar sobre o quadro alienador da educação, para, dai, apresentar propostas que levem à difusão de uma consciência crítica.
} 
nacional. São eles: "I - igualdade de condições para o acesso e permanência na escola; [...] X - valorização da experiência extraescolar; XI - vinculação entre a educação escolar, o trabalho e as práticas sociais”. (BRASIL, LDB, 1996). Tais princípios ainda são reforçados no inciso III do artigo 35 da LDB, que trata das diretrizes do Ensino Médio, e afirma que uma das finalidades dessa etapa da Educação Básica é “o aprimoramento do educando como pessoa humana, incluindo a formação ética e o desenvolvimento da autonomia intelectual e do pensamento crítico" (BRASIL, 1996).

Práticas que miram uma educação crítica e uma escola libertadora caminham para o cumprimento das exigências da lei geral da educação no Brasil. É importante observar que essas exigências não se restringem - ou não deveriam se restringir - às disciplinas das Ciências Humanas e Sociais, como a História, a Filosofia e a Sociologia, culturalmente tomadas como disciplinas que devem assumir um comprometimento crítico maior dentro de uma instituição de ensino. Os princípios e os fins da LDB sustentam toda a Educação Nacional e devem estar no cerne do processo educativo numa totalidade, independente da área ou da disciplina ministrada.

Também os Parâmetros curriculares nacionais do Ensino Médio (PCNEM), divulgados no Governo FHC com o intuito de difundir os princípios de uma reforma curricular, têm esse panorama de rompimento com modelos tradicionais que não inserem o estudante como sujeito ativo do sistema educacional. A publicação coloca como principal objetivo dos parâmetros currículares "desenvolver e consolidar conhecimentos das áreas, de forma contextualizada, referindo-os a atividades das práticas sociais e produtivas" (BRASIL, 2000a, p. 22-23) e leva essa ideia para o currículo de matemática, como observa-se na parte 3 do documento Ciências da natureza, matemática e suas tecnologias.

De fato, não basta revermos a forma ou metodologia de ensino, se mantivermos o conhecimento matemático restrito à informação, com as definições e os exemplos, assim como a exercitação, ou seja, exercícios de aplicação ou fixação. Pois, se os conceitos são apresentados de forma fragmentada, 
mesmo que de forma completa e aprofundada, nada garante que o aluno estabeleça alguma significação para as idéias isoladas e desconectadas umas das outras (BRASIL, 2000b, p. 43).

O documento aponta ainda uma direção do currículo para que o ensino da matemática tenha alguma significação para o aluno:

O currículo do Ensino Médio deve garantir também espaço para que os alunos possam estender e aprofundar seus conhecimentos sobre números e álgebra, mas não isoladamente de outros conceitos, nem em separado dos problemas e da perspectiva sócio-histórica que está na origem desses temas. Estes conteúdos estão diretamente relacionados ao desenvolvimento de habilidades que dizem respeito à resolução de problemas, à apropriação da linguagem simbólica, à validação de argumentos, à descrição de modelos e à capacidade de utilizar a Matemática na interpretação e intervenção no real (BRASIL, 2000b, p. 44).

No Governo do presidente Luiz Inácio Lula da Silva publicam-se as Orientações curriculares para o Ensino Médio, que aprofundariam as propostas dos PCNEM. São documentos que mantiveram - e em alguns aspectos até mesmo ampliaram - a perspectiva de um ensino crítico e ajustado a um contexto sociocultural, inclusive para o ensino da matemática, como aponta o volume 2 para as orientações das Ciências da natureza, matemática e suas tecnologias.

Ao final do ensino médio, espera-se que os alunos saibam usar a Matemática para resolver problemas práticos do quotidiano; para modelar fenômenos em outras áreas do conhecimento; compreendam que a Matemática é uma ciência com características próprias, que se organiza via teoremas e demonstrações; percebam a Matemática como um conhecimento social e historicamente construído; saibam apreciar a importância da Matemática no desenvolvimento científico e tecnológico (BRASIL, 2006, p. 69).

Os documentos orientadores de currículos mais recentes tentam transpor o ceticismo das teorias de reprodução social e cultural para alcançar uma escola que vá além dos processos de dominação. Eles abrem uma lacuna para ser preenchida com uma pedagogia de resistência e de afinidade também com a classe dominada. Tal como afirma Henry Giroux (1997), passa-se a ser possivel refletir sobre 
questões historicamente ignoradas e que vão muito além dos conteúdos pragmáticos das disciplinas.

\begin{abstract}
Que matérias serão ensinadas? Que formas de instrução serão usadas? Que tipos de objetivos serão desenvolvidos? Como podemos combinar os objetivos com formas correspondentes de avaliação? Por mais importantes que sejam estas questões, elas flutuam na superficie da realidade. Elas não incluem um foco sobre a natureza e função do currículo oculto, isto é, aquelas mensagens e valores que são transmitidos aos estudantes silenciosamente através da seleção de formas específicas em sala de aula, e das características definidoras da estrutura organizacional escolar. As mensagens de discriminação de raça, sexo e classe que espreitam por trás da linguagem dos objetivos e da disciplina escolar são convenientemente ignoradas (GIROUX, 1997, p. 36).
\end{abstract}

Tomaz da Silva (1999) sintetiza ainda com mais acuidade essa visão que Giroux procura do currículo dentro do sistema educacional:

\begin{abstract}
A escola e o currículo devem ser locais onde os estudantes tenham a oportunidade de exercer as habilidades democráticas da discussão e da participação de questionamento dos pressupostos do senso comum da vida social. Por outro lado, os professores e as professoras não podem ser vistos como técnicos ou burocratas, mas como pessoas ativamente envolvidas nas atividades da crítica e do questionamento, a serviço do processo de emancipação e libertação (SILVA, 1999, p. 54-55).
\end{abstract}

Silva (1999) ainda questiona a forma de ensino antidemocrática, na qual não há diálogos e ideias são impostas ao invés de debatidas e pactuadas. É um questionamento que dialoga perfeitamente com o conceito de Paulo Freire sobre a educação bancária, em que, segundo Freire (2005, p. 66), "a única margem de ação que se oferece aos educandos é a de receberem os depósitos, guardá-los e arquivá-los. Margem para serem colecionadores ou fichadores das coisas que arquivam".

Dentro desse panorama da educação matemática, desenvolvem-se reflexões e propostas que repudiam uma educação bancária para, em contrapartida, empenharem-se no fomento de um ensino da disciplina que coloque o aluno não mais como um mero receptáculo, pelo qual 
tentarão depositar conhecimentos geralmente inexpressivos e descontextualizados, mas num processo em que ele participará ativamente da construção e identificação dos conteúdos. Há uma necessidade de reconhecer, como sugere D’Ambrósio (1986, p. 42), “que a Matemática é, efetivamente, uma disciplina dinâmica e viva e reage, como qualquer manifestação cultural, a fatos socioculturais e, por conseguinte, econômicos".

\section{Etnomatemática e modelagem como instrumento}

Articular um ensino no qual o aluno não tenha um papel servil em relação à matemática e às questões tecnológicas é uma estratégia educacional que poderia, segundo Skovsmose (2001, p. 49-50), "ser talvez desenvolvida por uma abordagem etnomatemática caracterizada pela tese de familiaridade e pela abertura da situação ensinoaprendizagem". Etnomatemática, conceito desenvolvido pelo educador brasileiro Ubiratan D'Ambrosio (2005), refere-se à análise dos conhecimentos e conceitos de uma matemática própria de determinado contexto sociocultural. Diferente de ver em determinadas culturas resquícios do que poderia ser classificado enquanto uma "matemática acadêmica" (uma aplicação da geometria euclidiana por uma comunidade tribal, e.g.), o que D`Ambrosio busca é ressaltar o caráter próprio e cultural do pensamento desses sujeitos. ${ }^{11}$ Em outras palavras, encorajar "reflexões mais amplas sobre a natureza do pensamento matemático, do ponto de vista cognitivo, histórico, social, pedagógico" (D'AMBROSIO, 2005, p. 17).

O conceito de cultura é muito amplo e inclui a aglomeração
de atitudes e interesses próprios de uma faixa etária, de um
grupo sociocultural específico. Esses são claramente grupos
culturalmente diferenciados, e como tal estão sujeitos a todas
as peculiaridades que se aplicam à educação nesse caso, e
daí exigem a criação da flexibilidade curricular adequada. No
caso específico da educação matemática, não vemos outra

11 Etnomatemática é a matemática praticada por grupos culturais, tais como comunidades urbanas e rurais, grupos de trabalhadores, classes profissionais, crianças de uma certa faixa etária, sociedades indígenas, e tantos outros grupos que se identificam por objetivos e tradições comuns aos grupos (D’AMBROSIO, 2005, p. 9) 
alternativa além de se incorporar aos programas aquilo que chamamos etnomatemática (D’AMBROSIO, 1986, p. 41).

A etnomatemática projeta uma ruptura com o ensino tradicional, em que a matemática é uma disciplina soberana e incontestável, para se levar à escola a complexidade inerente ao ambiente multicultural em que a matemática pode ser desenvolvida. É uma ideia que está em acordo com o pensamento da educação matemática crítica de Skovsmose, que procura levar uma matemática que tende a equacionar no processo de aprendizagem os horizontes e pontos de vistas dos educandos, buscando uma aproximação professor-aluno e trazendo o elemento sociocultural para uma ciência tida historicamente imparcial.

A matemática pode, contudo, se ocupar de conhecimentos e compreensões que não se encaixam nas estruturas institucionalizadas por currículos e programas de pesquisa. Nesse sentido, seria possivel colocar em evidência a matemática presente no dia a dia de muitas profissões. Ela é parte integrante da tecnologia, do design e das tomadas de decisão, está nas tabelas, nos diagramas e nos gráficos. Basta folhear um jornal para encontrar muita matemática (SKOVSMOSE, 2014, p. 13-14).

Sistematizar um currículo e práticas pedagógicas que assimilam um universo sociocultural de grupos historicamente excluídos não deve ser confundido com privar o dominado do acesso à cultura dominante. $\mathrm{O}$ ponto central é justamente o contrário. Uma educação matemática crítica procura fortalecer a consciência de classe e permitir que relações de assimilação cultural não se transformem em relações de dominação e poder. Seria utilizar-se da matemática dentro de um conceito de materacia", em que "materacia não se refere apenas a habilidades matemáticas, mas também à competência de interpretar e agir numa situação social e politica estruturada pela matemática” (SKOVSMOSE, 2008, p. 16). As questões e os problemas matemáticos devem potencializar um campo de ação que permita aos estudantes trabalhar

12 Skovsmose (2008) usa o termo materacia em uma relação com o termo literacia, que é, por sua vez, a capacidade de um uso social e crítico da leitura e da escrita. 
uma educação matemática crítica e contextualizada, ao invés de insistir apenas na matemática pura e de semi-realidade.

Diferentes tipos de referência são possiveis. Primeiro, questões e atividades matemáticas podem se referir à matemática e somente a ela. Segundo, é possivel se referir a uma semi-realidade - não se trata de uma realidade que "de fato" observamos, mas de uma realidade construida, por exemplo, por um autor de um livro didático de matemática. Finalmente, alunos e professores podem trabalhar tarefas com referências a situações da vida real (SKOVSMOSE, 2008, p. 22).

Exercícios baseados na matemática pura e de semi-realidade estão fortemente inseridos na escola, traçando um horizonte de desligamento das práticas educativas com ambientes de investigação crítica da vida real. Como insinua Skovsmose (2001), uma forma de romper as fronteiras do ensino tradicional é trabalhar com a modelagem matemática.

[...] é extremamente importante que os estudantes aprendam sobre a construção de modelos, e a melhor maneira de aprender isso é construindo modelos. A tendência pragmática constrói-se sobre uma suposição filosófica acerca da matemática, que afirma que um aspecto essencial da matemática é sua utilidade (completamente contrário à filosofia estruturalista e formalista, que afirma que o aspecto essencial da matemática é sua "arquitetura lógica") (SKOVSMOSE, 2001, p. 40).

Barbosa $(2001$; 2004) descreve o uso de modelos matemáticos como estratégia importante para a matemática ser uma ferramenta crítica de interpretação de uma situação real. Segundo o autor (2001, p. 8), "o ambiente de Modelagem, baseado na indagação e investigação [...] busca estabelecer relações com outras áreas e o dia a dia”. Outra colaboração do seu estudo é entender que a modelagem, mais do que sua aplicabilidade em projetos, deve ser parte do currículo, servindo de base e orientação ao professor. Modelagem matemática não é simplesmente a aplicação da matemática em outras áreas de conhecimento. Mais do que uma definição reducionista e limitada, o importante é compreender a amplitude desse conceito, entender que "o ambiente de modelagem está associado à problematização e investigação" (BARBOSA, 2004, p. 75). Um 
local para, mais do que encontrar respostas, formular perguntas que levem a um raciocínio crítico.

\begin{abstract}
Creio que as atividades de Modelagem podem contribuir para desafiar a ideologia da certeza e colocar lentes criticas sobre as aplicações da matemática. Discussões na sala de aula podem agendar questões como as seguintes: $O$ que representam? Quais os pressupostos assumidos? Quem as realizou? A quem servem? Etc. Trata-se de uma dimensão devotada a discutir a natureza das aplicações, os critérios utilizados e o significado social (BARBOSA, 2004, p. 74).
\end{abstract}

Não há, portanto, um modelo pré-estabelecido, mas uma gama de possibilidades que pode ser criada e desenvolvida e que pode estar em trabalhos em grupos dentro da sala de aula ou projetos que buscam soluções além dos limites da escola. Numa análise dos estudos sobre modelagem nacionais e internacionais, Barbosa (2001) separa os casos de modelos matemáticos em três grupos: os que tanto a situaçãoproblema quanto as ferramentas necessárias para resolução são propostas pelo professor; os casos em que a situação-problema é proposta pelo professor, com as informações para a solução ficando a cargo de uma pesquisa externa dos alunos; e os casos nos quais os temas são trazidos pelos alunos. Em todos os casos o professor seria o "copartícipe" das investigações.

Não ocorre aqui uma classificação hierárquica dos métodos, mas sim a consideração de alternativas a serem elaboradas em aula. Modelos podem ser construídos partindo de notícias de jornais e revistas, identificando, manipulando e interpretando números de economia, política e esportes. É operar a matemática para entender e intervir criticamente sobre um assunto. Modelagem matemática está em uma pesquisa de preços de grandes supermercados em comparação com os pequenos "mercados de bairro". É a matemática na quantificação dos valores e na investigação de estratégias comerciais de estabelecimentos que vivem realidades distintas. Está, ainda, no desenvolvimento de um algoritmo para se definir uma hipotética distribuição de recursos 
financeiros de um programa social de assistência às famílias de baixa renda, como no exemplo exposto em Skovsmose (2001).

A modelagem matemática não pretende excluir e, nem mesmo, desqualificar o uso da matemática pura e de semi-realidade. São métodos importantes e que continuam - e devem continuar - tendo espaço no processo de ensino. O que se propõe aqui é trazer à tona é a relevância da modelagem e de outras práticas pedagógicas que veem na matemática uma ferramenta para se intervir criticamente em situações da vida real dos alunos.

\section{Considerações Finais}

O conceito de educação matemática crítica se insere na visão que, mesmo admitindo a escola como local de dominação e reprodução de desigualdades sociais, também entende que ela é um campo para a luta de classes, fértil para se desenvolver pensamentos e ideias que atendam aos interesses dos alunos. Não é por acaso que os dois dos expoentes da educação matemática crítica tratados aqui, a saber, o brasileiro Ubiratan D'Ambrosio e o dinamarquês Ole Skovsmose, tomam como base as ideias de Paulo Freire sobre uma educação para emancipação.

Nessa direção, considerar criticamente o próprio conhecimento da matemática é pensar, acima de tudo, no ambiente histórico-social que o sujeito está inserido. Num universo escolar em que interagem estudantes de diversos meios culturais, o conceito de etnomatemática torna-se de fundamental importância.

A etnomatemática projeta uma ruptura com o ensino tradicional, para o qual a matemática é uma disciplina soberana e incontestável, sendo por isso isenta das complexidades inerentes ao ambiente multicultural em que a matemática pode ser desenvolvida. Longe de uma visão tradicional de ensino, a etnomatemática se aproxima do pensamento da educação matemática crítica de Skovsmose, que procura levar uma matemática que tende a equacionar no processo de aprendizagem os horizontes e pontos de vistas dos educandos, buscando 
uma maior aproximação da relação professor-aluno e trazendo o elemento sociocultural para uma ciência tida historicamente como imparcial.

O uso de modelos matemáticos tem se revelado uma estratégia importante para que a educação matemática seja uma ferramenta crítica de interpretação de uma situação real. O ambiente de Modelagem, fundado no questionamento e investigação busca instituir relações com outras áreas e o dia a dia. Mais do que sua aplicabilidade em projetos, a modelagem deve ser parte do currículo, servindo de base e orientação ao professor.

Ainda que os estudos sobre a educação matemática crítica sejam relativamente recentes, a variedade de trabalhos articulados nos últimos anos indicam a relevância do assunto. É nessa relevância, sustentada principalmente pelos ideais educacionais freirianos, que este artigo se enquadra, ou seja, dentro de um espaço da educação que se alia a um ensino progressivo e libertador.

\section{Referências}

ALTHUSSER, Louis. Aparelhos ideológicos de Estado - Nota sobre os Aparelhos Ideológicos de Estado. Rio de Janeiro: Edições Graal, 1983.

ARANHA, Maria Lúcia. Filosofia da Educação. São Paulo: Moderna, 1990.

BARBOSA, Jonei Cerqueira. Modelagem matemática: o que é? Por que? Como?. Veritati, n. 4, p. 73-80, 2004. Disponivel em <http: / /www.educacional.com.br/upload/

blogSite/9468/9468082/26869/Modelagem-Matematica-

motivos8720129554.pdf >. Acesso: 12 de agosto de 2006.

- Modelagem na educação matemática: contribuições para o debate teórico. In: Reunião Anual da Anped. Rio de Janeiro: Anped, 2001. Disponivel em 
http:/ / www.ufrgs.br/espmat/disciplinas/funcoes_modelagem/modulo_ I/ modelagem_barbosa.pdf>. Acesso: 12 de agosto de 2016.

BOTTOMORE, Tom. Dicionário do pensamento marxista. Tradução de Waltensir Dutra. Rio de Janeiro: Jorge Zahar, 2001.

BOURDIEU, Pierre. A economia das trocas simbólicas. 6 ed. São Paulo: Perspectiva, 2005.

- A escola conservadora: as desigualdades frente à escola e à cultura. In: NOGUEIRA, Maria Alice; CATANI, Afrânio (Org.). Escritos de educação. Petrópolis: Vozes, 1998.

- Capital simbólico e classes sociais. Tradução de Fernando Pinheiro. Novos Estudos - CEBRAP (online). n. 96, p. 105-115, 2013. Disponivel em http:/ / novosestudos.uol.com.br/v1/contents/view/1522>. Acesso: 12 de agosto de 2016.

BRASIL, CONGRESSO NACIONAL. Lei de diretrizes e bases da educação nacional: LDB 9394/96. Brasília: Congresso Nacional, 1996.

—, MEC - SECRETARIA DA EDUCAÇÃO BÁSICA. Orientações Curriculares para o Ensino Médio. Vol. 2: Ciências da Natureza, Matemática e suas

Tecnologias. Brasília: MEC/SEB, 2006. , MEC - SECRETARIA DA EDUCAÇÃO MÉDIA E TECNOLÓGICA. Parâmetros curriculares nacionais (Ensino Médio): parte I: bases legais. Brasília: MEC/SEMTEC, 2000a.

, MEC - SECRETARIA DA EDUCAÇÃO MÉDIA E TECNOLÓGICA. Parâmetros curriculares nacionais (Ensino Médio): parte III: Ciências da natureza, matemática e suas tecnologias. Brasília: MEC/SEMTEC, $2000 b$. 
D'AMBROSIO, Ubiratan. Da realidade à ação: reflexões sobre educação e matemática. São Paulo: Summus; Campinas: Editora da Universidade Estadual de Campinas, 1986.

Etnomatemática: Elo entre as tradições e a modernidade. 2 ed. $2^{\text {a }}$ reimp. Belo Horizonte: Autêntica, 2005.

FREIRE, Paulo. Pedagogia da autonomia: saberes necessários à prática educativa. 41 ed. São Paulo: Paz e Terra, 2010.

Pedagogia do oprimido. 46 ed. Rio de Janeiro: Paz e Terra, 2005.

GIROUX, Henry A. Os professores como intelectuais: rumo a uma pedagogia crítica da aprendizagem. Tradução de Daniel Bueno. Porto Alegre: Artes Médicas, 1997.

LEONARDO, Nilza ; LEAL, Záira; ROSSATO, Solange. A naturalização das queixas escolares em periódicos científicos. In.: Revista Quadrimestral da Associação Brasileira de Psicologia Escolar e Educacional. São Paulo: volume 19, n. 1., 2015.

MÉSZÁROS, István. A educação para além do capital. Tradução de Education beyond capital. 2 ed. São Paulo: Boitempo, 2008.

SKOVSMOSE, Ole. Educação matemática crítica: a questão da democracia. Tradução de Abgail Lins e Jussara de Loiola Araújo. Campinas: Papirus, 2001.

Desafios da reflexão em educação matemática crítica. Tradução de Orlando de Andrade Figueiredo e Jonei Cerqueira Barbosa. Campinas: Papirus, 2008.

- Um convite à educação matemática crítica. Tradução de Orlando de Andrade Figueiredo. Campinas: Papirus, 2014.

SILVA, Tomaz T. da. Documentos de identidade: uma introdução às teorias do currículo. Belo Horizonte: Autêntica, 1999. 